\title{
Structure and function of the microbial community in a full-scale enhanced biological phosphorus removal plant
}

\author{
Correspondence \\ Per Halkjær Nielsen \\ phn@bio.aau.dk
}

Received 21 February 2007

Revised 9 August 2007

Accepted 30 August 2007
Yunhong Kong, Yun Xia, Jeppe Lund Nielsen and Per Halkjær Nielsen

Department of Biotechnology, Chemistry and Environmental Engineering, Aalborg University, DK-9000 Aalborg, Denmark

\section{INTRODUCTION}

An increasing number of wastewater treatment plants (WWTPs) are designed, or have been upgraded, to remove $\mathrm{C}, \mathrm{N}$ and $\mathrm{P}$ by using microbial activity in the process known as enhanced biological phosphorus removal (EBPR). This process is popular mainly because it is more environmentally friendly, due to reduced use of chemicals and low sludge production, compared to $\mathrm{P}$ removal by chemical precipitation (Seviour et al., 2003). The general understanding of design and operation of activated-sludge WWTPs has increased significantly in the last two decades, but occasionally EBPR WWTPs still suffer from suboptimal operation and breakdown of the P-removal process. These problems are believed to be due to poor understanding of the structure of the microbial community in EBPR

Abbreviations: AAE, Aalborg East; AAV, Aalborg West; DAPI, 4',6diamidino-2-phenylyindole; EBPR, enhanced biological phosphorus removal; FISH, fluorescence in situ hybridization; GAO, glycogenaccumulating organism; MAR, microautoradiography; OTU, operational taxonomic unit; $\mathrm{PAO}$, polyphosphate-accumulating organism; $\mathrm{PHA}$, polyhydroxyalkanoate; RDP, Ribosomal Database Project; RPAO, Rhodocyclus-related PAO; WWTP, wastewater treatment plant.

The GenBank/EMBL/DDBJ accession numbers for the $16 \mathrm{~S}$ rRNA gene sequences obtained in this study are DQ640653-D0640739.
WWTPs and insufficient knowledge of the ecophysiology of the key microbial populations.

Our understanding of the microbiology of EBPR WWTPs is to a large extent obtained from culture-independent studies using enriched cultures in well-controlled laboratory-scale reactors by using the full-cycle rRNA approach (Amann, 1995), as reviewed in detail by Mino et al. (1998) and Seviour et al. (2003). Some potentially important micro-organisms involved in the EBPR process have been identified in such laboratory-scale reactors, but only a few of them have been shown to be important in full-scale WWTPs. These are all uncultured organisms and can thus only be detected and quantified by using molecular methods such as fluorescence in situ hybridization (FISH) using group- or clone-specific oligonucleotide probes. FISH studies (Crocetti et al., 2000; Kong et al., 2004; Wong et al., 2005) in EBPR WWTPs have shown that polyphosphate-accumulating organisms (PAOs) related to Rhodocyclus (RPAO or Accumulibacter) (Crocetti et al., 2000; Hesselmann et al., 1999) and certain Actinobacteria (Kong et al., 2005) are abundant. Glycogen-accumulating organisms (GAOs) are present in many WWTPs and are mainly Gammaproteobacteria of the GB group (Competibacter) (Crocetti et al., 2002; Kong et al., 2002, 
2006; Nielsen et al., 1999), and in some WWTPs alphaproteobacterial Defluviicoccus (Burow et al., 2007). Otherwise, very little information exists about the other potentially important micro-organisms. Some filamentous bacteria, such as Chloroflexi (Bjornsson et al., 2002; Kragelund et al., 2007) and 'Candidatus Microthrix parvicella' (Blackall et al., 1996), may occasionally be present and cause bulking problems. Micro-organisms involved in $\mathrm{N}$ removal (nitrification/denitrification) may be present, and include betaproteobacterial ammoniaoxidizing bacteria (Mobarry et al., 1996) and nitrite oxidizers belonging to the phylum Nitrospira (Daims et al., 2001). Potential denitrifiers may be RPAO, Azoarcus, Thauera and Aquaspirillum (Thomsen et al., 2004, 2007; Wagner \& Loy, 2002).

The probe-defined microbial groups with known functions (ecophysiology) described above seem to account for only a small part of the total microbial communities in full-scale EBPR WWTPs. The PAOs and GAOs described above have been quantified in several studies (Kong et al., 2004, 2005, 2006) and form less than $30 \%$ of the total bacterial biovolume (measured by FISH against an EUBmix probe), often around 5-10\% each. Nitrifying bacteria are present, but their abundance is uncertain, while recent information about the denitrifiers suggests that they are fairly abundant (Thomsen et al., 2007). Thus, the identity and function of a significant fraction of the biomass in full-scale EBPR WWTPs may still be unresolved, stressing a need for more studies in full-scale WWTPs to identify other potentially important micro-organisms.

In this study we have chosen a full-scale EBPR WWTP with $\mathrm{N}$ removal and investigated the composition and biodiversity of its microbial community by using the full-cycle rRNA approach. Based on phylogenetic analysis and FISH probing, several novel probe-defined microbial groups were found in addition to other well-known microbial groups in EBPR WWTPs. Their potential functions were investigated using microautoradiography (MAR) combined with FISH (MAR-FISH) and FISH combined with histochemical staining. Quantitative FISH screening of samples from 10 full-scale EBPR WWTPs revealed that some of the novel groups were abundant in most EBPR WWTPs investigated, indicating the potential importance of these hitherto unknown groups in full-scale EBPR WWTPs.

\section{METHODS}

Sampling and WWTP description. Activated-sludge samples for DNA extraction were obtained from the Skagen WWTP. The Skagen WWTP has a Biodenipho configuration (Seviour et al., 1999) in which influent is mixed with the activated sludge in anaerobic tanks before entering tanks with alternating denitrifying and nitrifying conditions. The Skagen WWTP has operated with stable biological P removal, nitrification and denitrification for many years (effluent standards: total $\mathrm{P}<1 \mathrm{mg} \mathrm{P}^{-1}$, total $\mathrm{N}<8 \mathrm{mg} \mathrm{N}^{-1}$ ). Anaerobic $\mathrm{P}$ release tests performed regularly after acetate addition (Tykesson et al., 2006) have shown a $\mathrm{P}$ release of $5-8 \mathrm{mg} \mathrm{P}$ (g volatile suspended solids) ${ }^{-1}$ (VSS) during this period. The Skagen plant receives wastewater with a high content of organic matter (fish industry and domestic wastewater) and a typical influent has a total chemical oxygen demand (COD) of $1500 \mathrm{mg} \mathrm{O}_{2} \mathrm{l}^{-1}$ and a total $\mathrm{P}$ of $25 \mathrm{mg}$ $\mathrm{P}^{-1}$. The plant treats wastewater corresponding to 280000 population equivalent (PE). Sludge samples for clone library construction were collected in July 2003 from the oxic (nitrifying) tanks and transferred within $1-2 \mathrm{~h}$ to the laboratory. Sludge samples for quantitative FISH were collected in February 2006. Quantitative FISH was also performed on sludge samples from the WWTPs Aalborg East [AAE; PE $160000,475 \mathrm{mg} \mathrm{O}_{2} \mathrm{l}^{-1}$ influent total COD (ITC) and $7 \mathrm{mg} \mathrm{P}^{-1}$ total P (TP)], Aalborg West (AAV; PE 300000 , $446 \mathrm{mg} \mathrm{O}_{2} \mathrm{l}^{-1}$ ITC, $6 \mathrm{mg} \mathrm{P}^{-1} \mathrm{TP}$ ), Egaa (PE $90000,592 \mathrm{mg} \mathrm{O}_{2} \mathrm{l}^{-1}$ ITC, $9 \mathrm{mg} \mathrm{P}^{-1} \mathrm{TP}$ ), Helsingborg (PE 120000 , no data available for ITC and TP), Bjergmarken (PE 83000, $650 \mathrm{mg} \mathrm{O}_{2} \mathrm{l}^{-1}$ ITC, $10 \mathrm{mg}$ $\mathrm{P}^{-1} \mathrm{TP}$ ), Ejby Mølle (PE 284000, $905 \mathrm{mg} \mathrm{O} \mathrm{l}^{-1}$ ITC, $8 \mathrm{mg} \mathrm{P} \mathrm{l^{-1 }}$ TP), Odense Nordøst (PE 25000, $407 \mathrm{mg} \mathrm{O}_{2} \mathrm{l}^{-1} \mathrm{ITC}, 7 \mathrm{mg} \mathrm{P} \mathrm{l}^{-1}$ TP), Varde (PE $22000,321 \mathrm{mg} \mathrm{O}_{2} \mathrm{l}^{-1}$ ITC, $6 \mathrm{mg} \mathrm{P} \mathrm{l}^{-1} \mathrm{TP}$ ), Lynetten (PE $650000,730 \mathrm{mg} \mathrm{O}_{2} \mathrm{l}^{-1} \mathrm{ITC}, 10 \mathrm{mg} \mathrm{P}^{-1} \mathrm{TP}$ ), and Damhusån (PE $220000,500 \mathrm{mg} \mathrm{O}_{2} 1^{-1}$ ITC, $8 \mathrm{mg} \mathrm{P}^{-1} \mathrm{TP}$ ). The total effluent $\mathrm{P}$ of all these plants is $<1 \mathrm{mg} \mathrm{l}^{-1}$. All data about the influent COD and total $\mathrm{P}$ were mean values for 2006. All these WWTPs, except AAE, AAV, Egaa and Helsingborg, which were sampled three times on different dates over a period of 12-31 months, were sampled once. All WWTPs, except Helsingborg, which is a Swedish WWTP, are Danish WWTPs mainly treating domestic wastewater with some industrial contribution, and all have a Biodenipho configuration (most Danish EBPR WWTPs have a Biodenipho configuration).

FISH. Sludge fixation and FISH probing were carried out as previously described (Kong et al., 2006). The oligonucleotide probes EUBmix [equimolar concentrations of EUB338 (Amann et al., 1990) EUB338II and EUB338III (Daims et al., 1999)], NONEUB (Wallner et al., 1993), ALF 968 (Neef, 1997), HGC69a (Roller et al., 1994), LGCmix [equimolar concentrations of LGC354A, LGC354B and LGC354C (Meier et al., 1999)], TM7905 (Hugenholtz et al., 2001), Ntspa1413 (Maixner et al., 2006), HoAc1402 (Juretschko et al., 2002), CFX1223 and GNSB-941 (Bjornsson et al., 2002), Actino-221, Actino651 (Kong et al., 2005), and PAOmix [equimolar concentrations of PAO651, PAO462 and PAO846 (Crocetti et al., 2000)], GB_G1 (GAOQ989) (Crocetti et al., 2002) and GB_G2, GB_1\&2, GB_3, GB_4, GB_5, GB_7 (Kong et al., 2002), GB_6 [Gam1019 (Nielsen et al., 1999)], Cluster 6a-192 (Adamczyk et al., 2003), ZRA23a (Rossello-Mora et al., 1995), Azo644 (Hess et al., 1997), Thau-646 (Lajoie et al., 2000), Aqs997 (Thomsen et al., 2004), Sap309 (Schauer \& Hahn, 2005), CF319a and CF319b (Manz et al., 1996) were used for FISH. All the probes, except the EUBmix, which was labelled with FLUOS, were labelled with either Cy3 or Cy5 (only for specificity check). The specificities, hybridization requirements, use of competitors and reference information for most of the probes are all described in probeBase (Loy et al., 2003).

Clone library construction, clone screening, and sequencing. The community DNA was extracted by using the FastDNA kit used with the FastPrep instrument according to the protocol recommended by the supplier (Qbiogene). Bacterial primers 8F (Brosius et al., 1981) and 1492R (Lane, 1991) were used for PCR. The PCR running conditions, PCR product ligation, cloning, clone screening by using denaturing gradient gel electrophoresis (DGGE), and sequencing were carried out following procedures described previously (Kong et al., 2005).

Phylogenetic analysis. The $16 \mathrm{~S}$ rRNA gene sequences obtained were uploaded and aligned with ARB software (Ludwig et al., 2004). The aligned sequences were checked in the Ribosomal Database Project (RDP) (Cole et al., 2005) for chimeric artefacts using the CHECK_CHIMERA tool and Bellerophon (Huber et al., 2004), before 
being compared in GenBank using the BLAST program (Altschul et al., 1990). Then, the sequences and their closely related sequences were aligned in ARB and Mega3 (Kumar et al., 2004), and phylogenetic trees were calculated and built on the basis of the neighbour-joining, minimum-evolution, maximum-parsimony and PHYLIP-distance methods provided in the software using the default setups. The topology of the trees built for the Bacteroidetes (including Chlorobi) and proteobacterial clones did not significantly change, compared with those shown in Figs 1 and 2. Sequence similarity was calculated based on the neighbour-joining trees using the function provided in the ARB software.

Biodiversity analysis. The homogeneous coverage was calculated using the equation $C=\left[1-\left(n 1 \times N^{-1}\right)\right] \times 100 \%$, as described by Singleton et al. (2001), in which $C$ is the homogeneous coverage, $n 1$ is the number of OTUs (operational taxonomic units) with only one sequence, and $N$ is the total number of $16 \mathrm{~S}$ rRNA genes analysed. The threshold value used for OTU definition was $97 \%$. The species richness was estimated by dividing the number of OTUs by $C$.

Oligonucleotide probe design and specification. A number of oligonucleotide probes were designed using the function provided in the ARB software. The specificity of these probes was further confirmed by the use of the Check Probe program in the RDP. Only the probes that received enough FISH signal to allow optimization of stringency are listed in Table 1.

All the probes designed in this study targeted uncultured bacteria that did not have close cultured relatives. Fixed activated-sludge samples from the Skagen WWTP, therefore, were used to optimize the formamide concentration that was used in FISH probing. The specific formamide concentration used for a probe was determined by FISH probing in a series of formamide concentrations from 0 to $60 \%$ at $5 \%$ increments. Six probes were found to hybridize with more than $1 \%$ of all eubacteria (Table 1) and were evaluated in more detail. Probes covering the novel groups found in the Betaproteobacteria and Gammaproteobacteria were applied together with probe BET42a (with unlabelled GAM42a as competitor) and probe GAM42a (with unlabelled BET42a as competitor), respectively. Similarly, Bac111 was applied together with Sap309 targeting most members of the Saprospiraceae. A competitor $\mathrm{cBac} 111$ was designed for probe Bac111. Fixed Haliscomenobacter hydrossis (ATCC 27775), having one mismatch with probe Bac111, was used as negative control for the probe. No negative control was used for probe Bac993, as it had more than two mismatches with any available sequences. No negative control was used for probe Bet65, as it had more than two (at least three) mismatches with available pure cultures. A negative control was also not used for probe Gam445, which, except for having two mismatches with one clone (DQ490001) of bacterial isolates from a hot spring $\left(80^{\circ} \mathrm{C}\right)$, had more than two mismatches with all available sequences in the GenBank database. No negative control was used for probe Gam 829 because no publicly available pure cultures within two mismatches were available, and no appropriate probe-defined groups could be used. For probe Bet135, which had at least three mismatches with any available pure culture, uncultured RPAO hybridizing with PAOmix and one mismatch with probe Bet 135 were used as negative controls (tested on samples from the Skagen, AAV and AAE WWTPs). The specificity (number of mismatches) check for all these probes was carried out through GenBank by November 2006. In FISH probing of all samples, probe NONEUB was used as a negative control.

Quantitative FISH. FISH for quantitative biovolume analysis was carried out on six-well gelatin-coated slides. FISH images were taken with the Zeiss LSM510 Meta microscope, as previously described (Kong et al., 2004). The biovolumes of the probe-defined microbial phylum, class, group or clones were estimated by measuring the percentage of the area fluorescing with a probe (Cy3-labelled) in relation to the area fluorescing with the EUBmix probe (FLUOSlabelled) on the same images. In all image captures the optical slice taken by the confocal laser microscope was adjusted to $1.3 \mu \mathrm{m}$ to ensure that only FISH signals from a thin layer of biomass were sampled each time. For each enumeration, at least 24 images were taken from three different wells (eight from each well). The three mean values from each of the eight measurements were used to calculate the biovolume (mean value) and its SD.

MAR-FISH and FISH combined with histochemical staining. The MAR-FISH procedure and the radioactive chemicals used are detailed in Kong et al. (2004) and Lee et al. (1999). Fresh activatedsludge samples from Skagen were used for radioactive incubations. FISH combined with Neisser staining for polyphosphate and Nile blue staining for polyhydroxyalkanoates (PHAs) were carried out following the procedures described by Kong et al. (2004, 2006). FISH combined with $4^{\prime}, 6$-diamidino-2-phenylyindole (DAPI) staining was carried out as described previously (Kong et al., 2001).

\section{RESULTS}

\section{Phylogenetic analysis of Skagen sludge}

A clone library from the Skagen WWTP was constructed and 87 almost full-length $16 \mathrm{~S}$ rRNA gene sequences were retrieved. No chimerical sequences were found. After comparison with $16 \mathrm{~S}$ rRNA gene sequences available in the GenBank database, 78 OTUs in nine different bacterial phyla were identified by using $97.0 \%$ similarity as the threshold. Three sequences could not be convincingly aligned into any known bacterial phylum.

Interestingly, almost half of the sequences retrieved (41 out of 87) formed 33 OTUs in the phylum Bacteroidetes (Fig. 1). All except OTU 33, which had a cultured bacterium Runella zeae as its closest relative (91.6\% similarity), were related to uncultured environmental clones. Only OTUs 2, 4 and 18 shared more than $97.0 \%$ similarity with available sequences in GenBank, whereas the others had 80.3-96.6\% similarity, indicating a high and undescribed diversity of Bacteroidetes in the Skagen WWTP. OTUs 1-17 were distantly related to $H$. hydrossis of the family Saprospiraceae ( $<89.0 \%$ similarity). Other OTUs clustered to sequences in the families Flavobacteriaceae, Flexibacteriaceae, Bacteroidaceae and Sphingobacteriaceae.

The phylum Proteobacteria encompassed 31 clones forming 30 OTUs (Fig. 2). Among the 14 OTUs in the Betaproteobacteria, OTUs 41 and 43 had cultured species Thauera sp. and Nitrosomonas sp., respectively, and clones 47 and 49 had Comamonadaceae sp. as closest relatives, whereas all others were related to sequences of uncultured bacteria. The betaproteobacterial RPAO were represented by OTUs 36 and 37 (>97.0\% similarity). Eight OTUs were found in Gammaproteobacteria and all were related to uncultured bacterial clones. Two of them clustered to known GAOs, the GB group in Gammaproteobacteria (Kong et al., 2002) (OTUs 54 and 55, 94.1-97.6\% similarity). Among the Alphaproteobacteria, four OTUs were identified. Two had Rhodobacter sp. and Methylocystis 


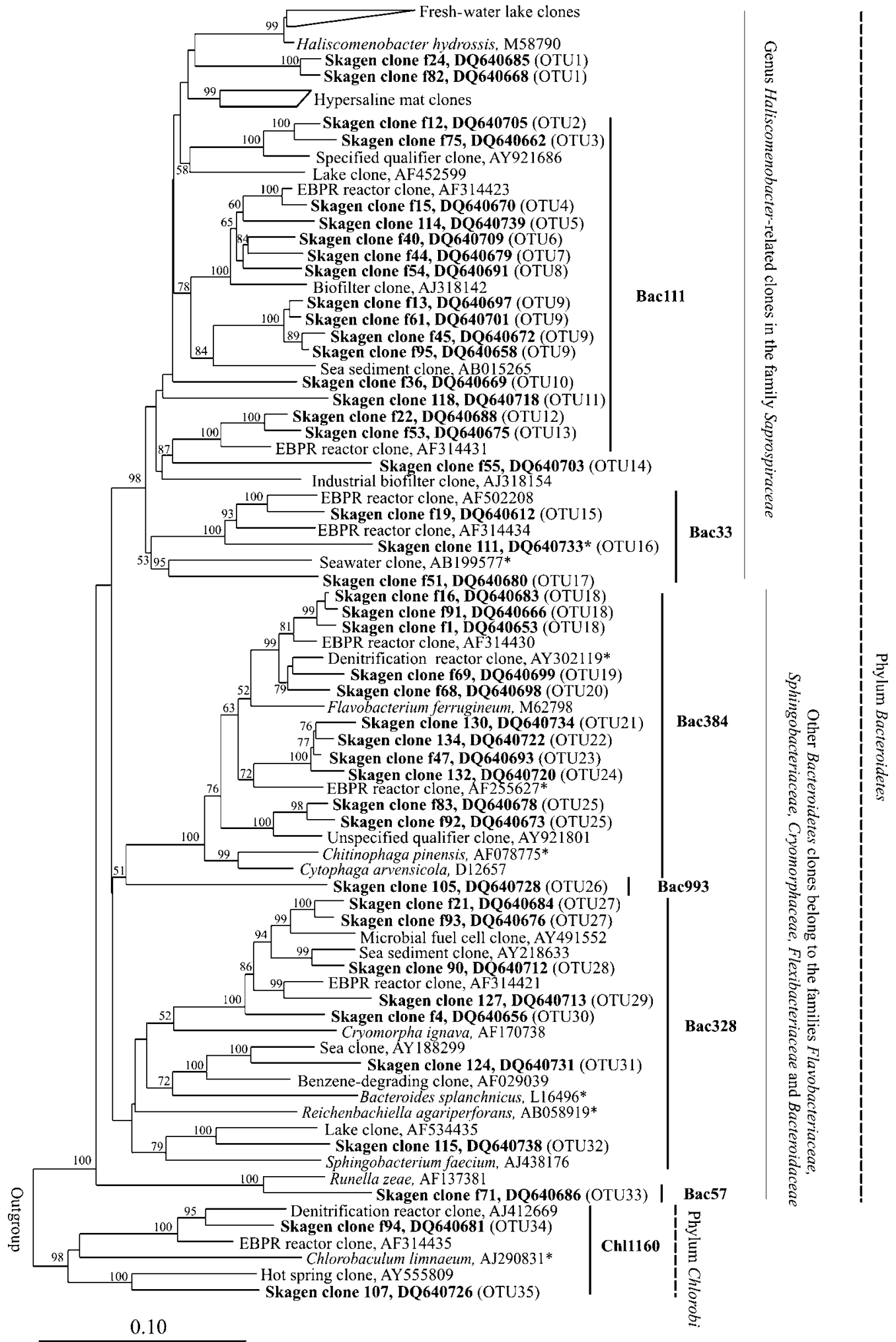

Fig. 1. A distance tree (neighbour-joining) built using the Bacteroidetes and Chlorobi 16S rRNA gene sequences retrieved in this study. Sequences with names in bold type were obtained from this study. ${ }^{*}$ Clones with $>1$ mismatch with the probe; all the other clones have 0 mismatches with the probe. The probes designed for the clones are also shown. The bootstrap values (only those $>50 \%$ are shown) were calculated based on 1000 resamplings. Scale bar, 1 substitution per 10 nucleotides. 


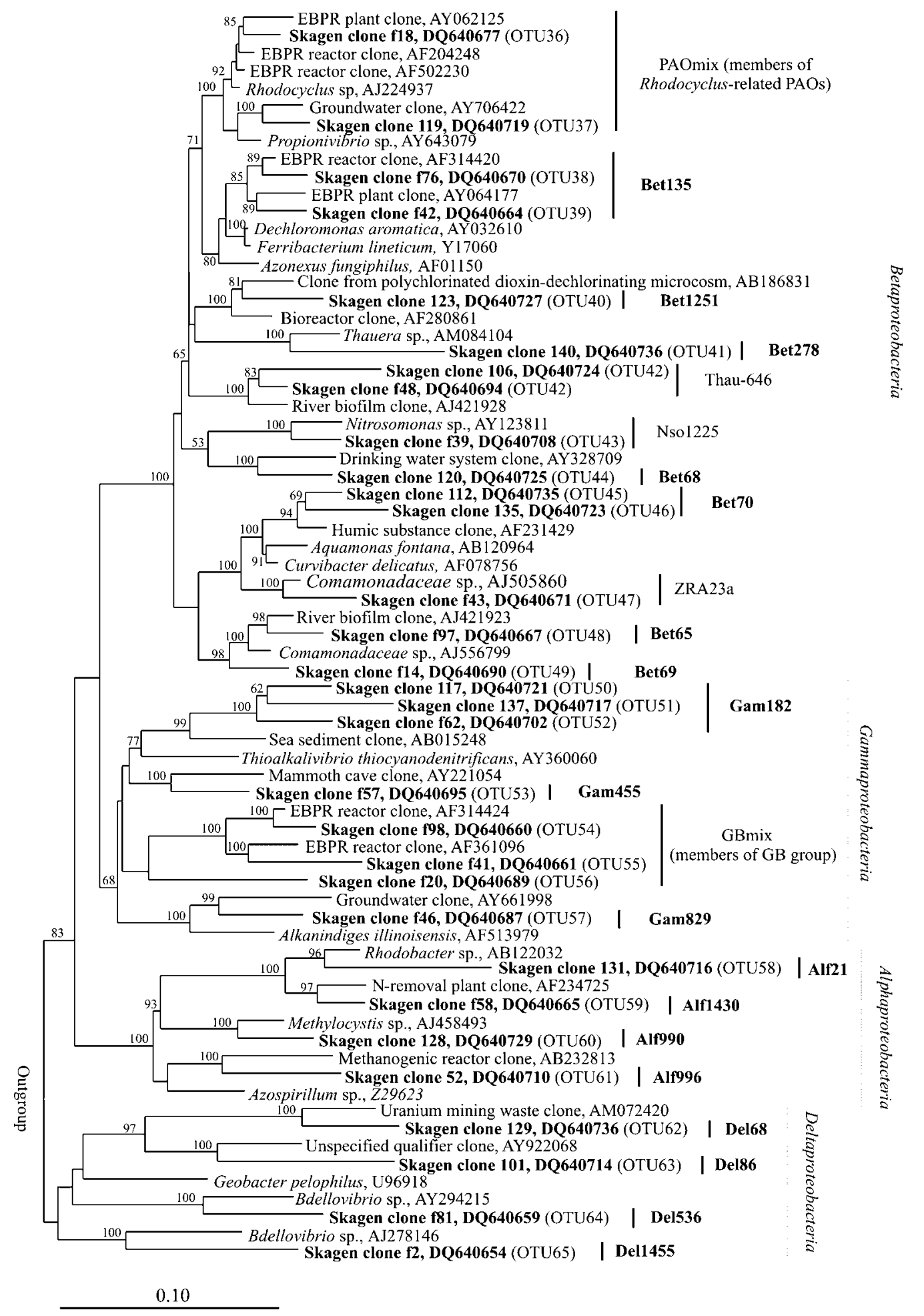

Fig. 2. A distance tree (neighbour-joining) built using the proteobacterial $16 \mathrm{~S}$ rRNA gene sequences retrieved in this study. Sequences in bold type were obtained from this study. ${ }^{*}$ Clones with $>1$ mismatch with the probe; all the other clones have 0 mismatches with the probe. The probes designed in this study are shown in bold type. The bootstrap values (only those $>50 \%$ are shown) were calculated based on 1000 resamplings. Scale bar, 1 substitution per 10 nucleotides. 
Table 1. Names, specificities and formamide concentrations of probes (including a competitor) designed and used in this study

\begin{tabular}{|c|c|c|c|}
\hline Probe name (systematic name ${ }^{\star}$ ) & Sequence $\left(5^{\prime}-3^{\prime}\right)$ & Specificity $\dagger$ & $\begin{array}{c}\text { FA } \ddagger \\
(\%)\end{array}$ \\
\hline Bet65 (S-S- $\beta$ Prot-0065-a-18) & CAGTTGCCCCGCGTACCG & Skagen clone $\mathrm{f} 97$ (closely related to Comamonadaceae) & 30 \\
\hline Bet135 (S-S- $\beta$ Prot-0135-a-21) & ACGTTATCCCCCACTCAATGG & $\begin{array}{l}\text { Skagen clones } 42 \text { and } 76 \text {, and eight closely related } \\
\text { Rhodocyclaceae clones }\end{array}$ & 45 \\
\hline Gam829 (S-S- $\gamma$ Prot-0832-a-21) & GACTCAAGGTCCCCCAACGGC & Skagen clone f46 (distantly related to Alkanindiges) & 35 \\
\hline Gam455 (S-S- $\gamma$ Prot-0455-a-20) & CTGACGTATTCGGCCAGTGC & Skagen clone 57 (distantly related to Thioalkalivibrio) & 35 \\
\hline Bac111 (S-S-Sap-0111-a-18) & TGTACGCGTTACTCACCC & $\begin{array}{l}\text { Skagen clones } \mathrm{f} 12, \mathrm{f} 13, \mathrm{f} 15, \mathrm{f} 22, \mathrm{f} 36, \mathrm{f} 40, \mathrm{f} 44, \mathrm{f} 45, \mathrm{f} 53, \mathrm{f} 54, \mathrm{f} 61 \text {, } \\
\mathrm{f} 75, \mathrm{f} 95,114 \text { and } 118 \text {, and } 44 \text { closely related Saprospiraceae } \\
\text { clones }\end{array}$ & 25 \\
\hline cBac111 & CGTACGCGTTACTCACCC & Some fresh-water lake and sea clones in Saprospiraceae & \\
\hline Bac993 (S-S-Bac-0994-a-20) & GGCAACCATCACGCGCATTC & Skagen clone 105 (distantly related to Cytophaga) & 35 \\
\hline
\end{tabular}

*According to Alm et al. (1996).

$\dagger$ Only clones longer than 1200 bp were examined.

¥Formamide concentration.

sp. ( $86.4 \%$ and $94.5 \%$ similarity, respectively) as their closest relatives, whereas the other two were related to uncultured bacteria. Four OTUs could be identified in the Deltaproteobacteria, two of them sharing 85.8-87.1\% similarity with Bdellovibrio sp., whereas the other two were distantly related to uncultured bacteria.

The candidate phylum TM7 was represented by four clones (DQ640696, DQ640706, DQ640707 and DQ640711), each representing one OTU (not shown in figures). They were all distantly related ( $<92.9 \%$ similarity) to clones obtained from soil (AF507687) and a biofilter (AJ318200). Phylum Gematimonadetes was represented by two clones (DQ640655 and DQ640715), each representing one OTU. Similarly, two clones fell into the phylum Chlorobi, each representing an OTU (OTUs 34 and 35) (Fig. 1). The four phyla Nitrospira, Planctomycetes, Acidobacteria and Chloroflexi were each represented by only one clone (DQ640657, DQ640663, DQ640674 and DQ640704, respectively), representing four OTUs in total. Except for the OTU affiliated with Nitrospira (in sublineage 1), which was closely related to a clone from an EBPR system (AF314422, 98.9\% similarity), the other three OTUs were related to clones from an N-removal WWTP (BX294895), a soil clone (AY289400) and a sea-sediment clone (DQ351765).

The homogeneous coverage of the clone library was calculated to be $19 \%$, using $97 \%$ similarity as the threshold for an OTU, and the species richness was 411 .

\section{Design of new oligonucleotide probes and FISH probing}

In order to screen the microbial community in the Skagen WWTP for potentially abundant and undescribed microbial groups, 30 oligonucleotide probes were designed on the basis of the 16S rRNA gene sequences retrieved. The probes were designed for almost all the hitherto undescribed sequences; the names and coverage of most of these probes are also shown in Figs 1 and 2. When they were tested for specificity and optimum formamide concentration (see Methods), six of the new probes hybridized with at least $1 \%$ (naked eye estimation) of the biomass in the Skagen sludge, providing a clear FISH signal, which indicates that the groups represented by the clones were potentially abundant in the sludge. The name, sequence, specificity and formamide concentration of the six probes showing a clear FISH signal and optimized for their formamide concentration are listed in Table 1.

Probe Bac111 hybridized mainly with rods attached to filamentous bacteria (epiflora) and a few filaments (Fig. 3b). All the bacterial cells hybridized with Bac111 also hybridized with Sap309, which targets most members in the family Saprospiraceae of the phylum Bacteroidetes. Bac993 hybridized with very thin filaments inside the flocs (Fig. 3d). None of the bacterial cells hybridizing with probes Bac111 and Bac993 hybridized with a probe mixture of CF319a and CF319b designed for the Cytophaga-Flavobacterium group of Bacteroidetes. Bet135 hybridized with cocci of different sizes (Fig. 3c), and some of them (30\%, naked eye estimation) also hybridized with the PAOmix probe, which targets RPAO. Bet65 hybridized with short rods in clusters (Fig. 3e), and Gam829 with cocci dispersed in sludge flocs (Fig. 3a). Gam 445 hybridized with short rods in clusters (not shown). All bacterial cells hybridizing with Bet135 and Bet65 also hybridized with BET42a designed for class Betaproteobacteria in the phylum Proteobacteria, and all cells hybridizing with Gam445 and Gam829 also hybridized with GAM42a designed for class Gammaproteobacteria.

\section{Composition of the microbial community in the Skagen WWTP}

The dominant microbial groups in the Skagen WWTP were determined by applying quantitative FISH to fresh 


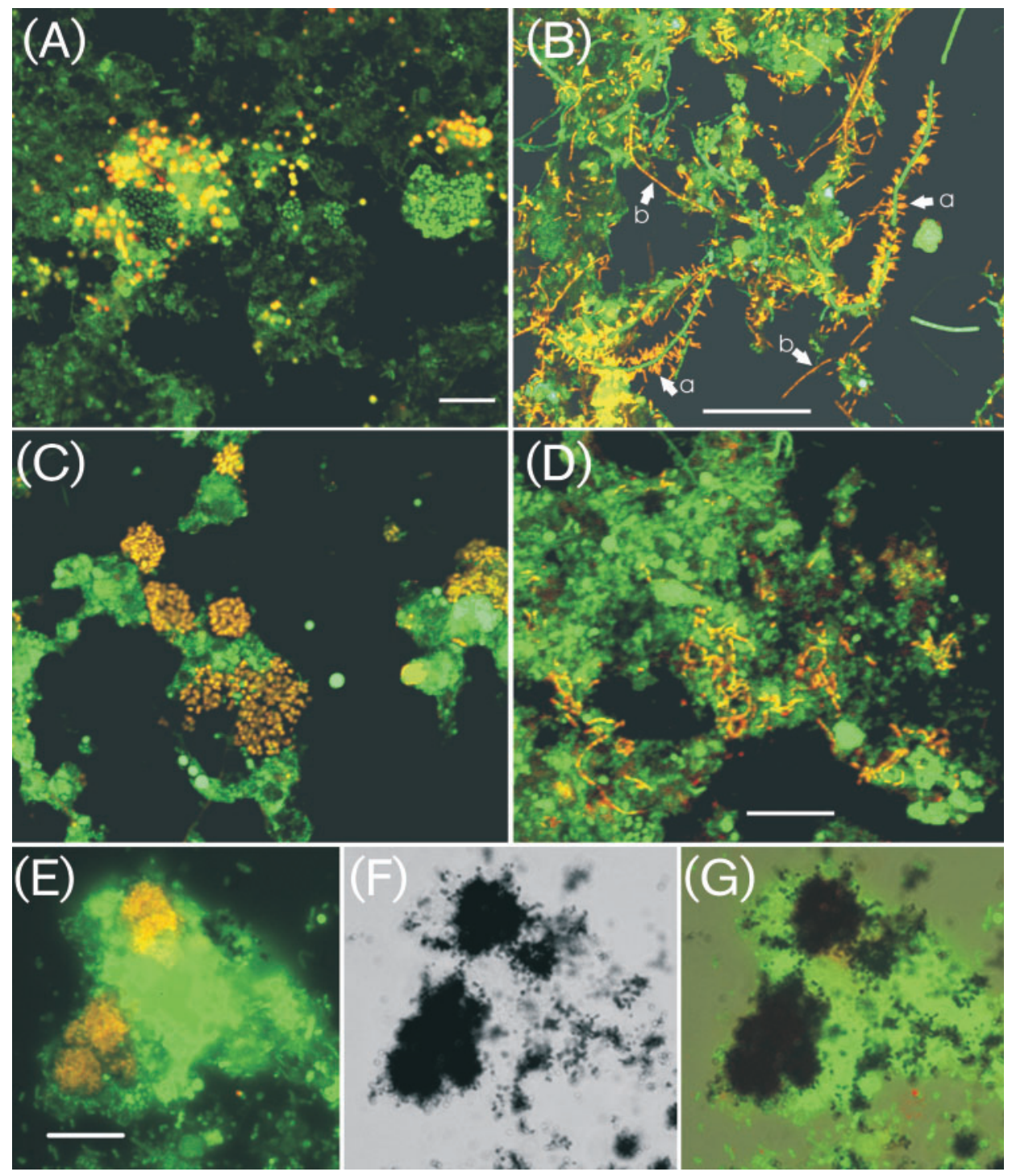

Fig. 3. Images of activated-sludge samples from the Skagen plant after FISH and MAR. (A-E) FISH images after colour combination. The images from group- or clone-level probes are labelled in red and those from the EUBmix are labelled in green. The yellow (combination of red and green) cocci in (A) hybridized with probe Gam829, the rods (e.g. arrow a) attached to filamentous bacteria and filaments (e.g. arrow b) in (B) hybridized with Bac111, the coccobacilli in (C) hybridized with Bet135, the filamentous bacteria in (D) hybridized with Bac993, and the short rods in (E) hybridized with Bet65. Bars in (A), (B), (D) and $(E), 10 \mu \mathrm{m}$. (A) and (C) share the same bar; (E), (F) and (G) share the same bar. (F) MAR image of (E); (G) overlay image of (E) and $(F)$ showing that bacteria hybridizing with Bet65 took up acetate under anaerobic conditions.

sludge with the probes designed in this study as well as other available probes. Bacteria hybridizing with the EUBmix probe constituted $85 \pm 5 \%$ (SD) of the biovolume of micro-organisms stained by DAPI. Assuming that the total biovolume measured with the various probes was $100 \%$ of the bacterial biovolume that hybridized with the EUBmix probe (the value actually determined was $103 \pm 22 \%$ ), all probe-defined groups or phyla that accounted for more than $1 \%$ of the biovolume are depicted in Fig. 4. Most bacteria detected belonged to the Proteobacteria (56\%), Bacteroidetes (17\%), Actinobacteria
(13\%) and Chloroflexi (8\%). Bacteria belonging to the Gemmatimonadetes, Planctomycetes, Acidobacteria and Firmicutes accounted for a minor fraction $(<1 \%)$ and are not shown in Fig. 4.

Two different probe-defined groups were detected in the phylum Bacteroidetes. They were Bac111- and Bac993defined groups constituting $16 \%$ and $\sim 1 \%$ of the bacterial biovolume, respectively. Betaproteobacteria constituted $\sim 40 \%$ of the bacterial biovolume. These were uncultured Aquaspirillum-related bacteria (16\%), Rhodocyclus-related 


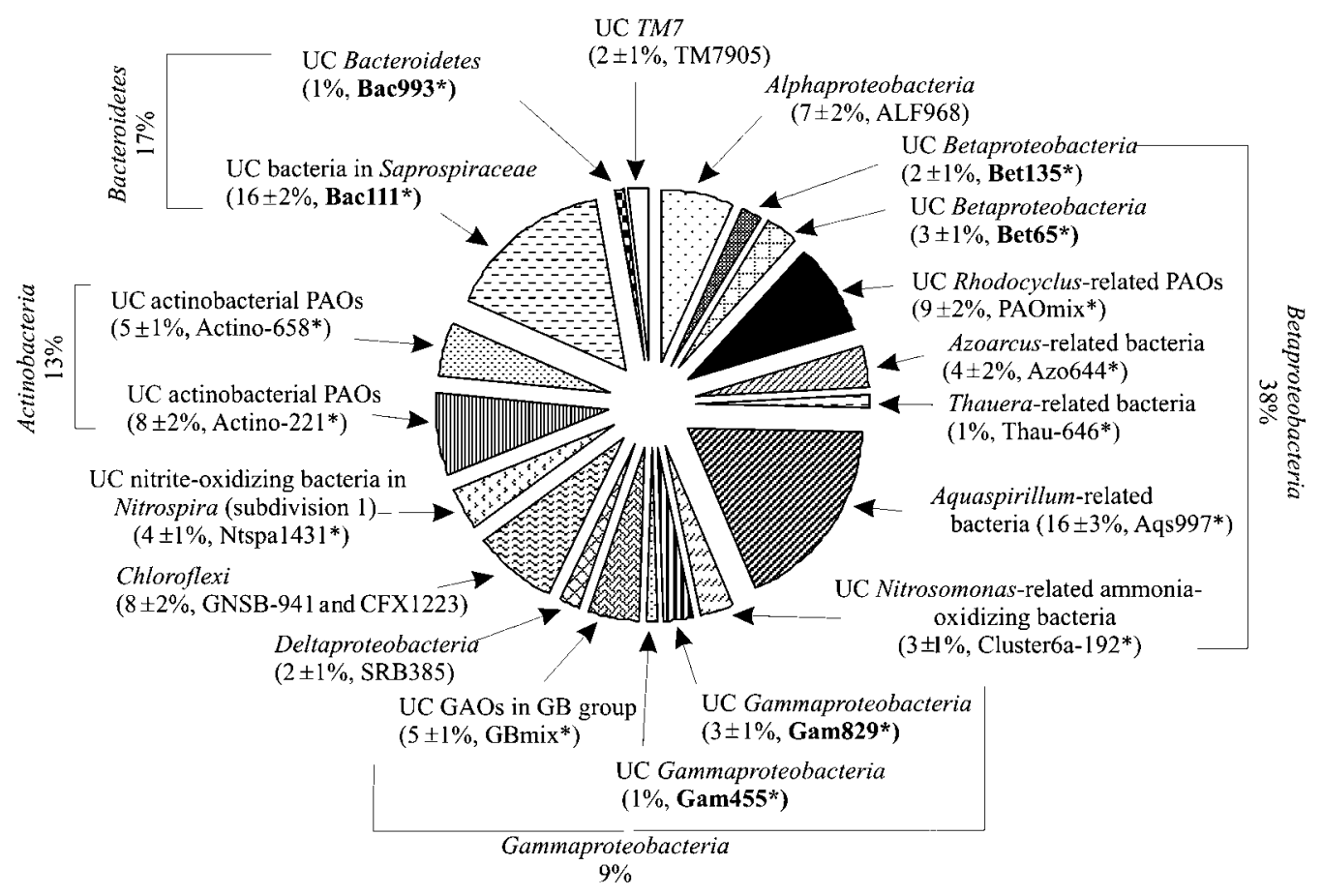

Fig. 4. The composition of the microbial community of the Skagen WWTP determined by using quantitative FISH with individual phylum-, subdivision- and group-level probes against the EUBmix probe. The probes used in quantitative FISH are also listed in parentheses after the percentages. The probes with names in bold type were designed for this study. ${ }^{\star} \mathrm{Group}-$ or clone-level probes. UC, uncultured.

PAOs (9\%), Azoarcus-related bacteria (4\%), the Bet65defined group (3\%), Nitrosomonas ammonia-oxidizing bacteria (3\%), the Bet135-defined group $(2 \%)$ and Thauera-related bacteria (1\%). Betaproteobacteria hybridizing with probe BET42a constituted $30 \pm 5 \%$ of the bacterial biovolume. The Gammaproteobacteria detected were mainly GAOs (5\%) belonging to the GB group (subgroups 3 and 5-7) and bacteria belonging to the Gam829-defined group (3\%) and the Gam445-defined group (1\%). The broad GAM42a probe for Gammaproteobacteria hybridized with $8 \pm 3 \%$ of all eubacterial cells. Actinobacteria detected were mainly from two probedefined groups: actinobacterial PAOs hybridizing with Actino-221 (8\%) and Actino-658 (5\%). The Chloroflexi formed $8 \%$ of the biovolume and it was noticed that some of them did not hybridize with the EUBmix. The Nitrospira and TM7 phyla constituted 4 and $2 \%$ of the biovolume, respectively. A further analysis of the nitrite oxidizers showed that they belonged to sublineage 1 of genus Nitrospira, hybridizing with probe Ntspa1431.

\section{Ecophysiology of the novel probe-defined microbial groups}

Some physiological traits were investigated for the newly identified probe-defined microbial groups by using MARFISH and FISH combined with histochemical staining. These included uptake of various organic substrates under aerobic and anaerobic conditions, uptake of selected compounds with nitrate present as the potential electron acceptor, and possible storage of polyphosphate and PHA. Of the six probe-defined microbial groups, four were investigated in detail in this study. Gam829-defined cocci were present in too low numbers in the sludge tested with MAR for reliable observations. Bac111-defined epiflora is a group of protein hydrolysers in activated sludge (Xia et al., 2007), and their detailed phylogeny and ecophysiology will be presented in another study (Y. Xia and others, unpublished results).

More than $50 \%$ of the members of the Bet135-, Bet65- and Gam445-defined groups were able to take up acetate, pyruvate, and some amino acids including aspartic acid, glutamic acid and leucine, under both aerobic and anaerobic conditions. They could not take up formic acid, ethanol, oleic acid and glycine. Most bacteria in each probe-defined group took up glucose under anaerobic but not under aerobic conditions, indicating that their glucose uptake under anaerobic conditions was due to uptake of radioactive fermentation products (e.g. acetate or pyruvate) produced from fermentation of labelled glucose by other micro-organisms (Kong et al., 2004). All three groups were able to grow on acetate under aerobic conditions, but not under anaerobic conditions. This was investigated by using a long preincubation period with unlabelled acetate under different electron acceptor conditions before 
addition of labelled acetate (Kong et al., 2004). Most bacteria in each group could take up labelled acetate after $9 \mathrm{~h}$ aerobic preincubation, but none could do it after $6 \mathrm{~h}$ anaerobic preincubation, indicating that they were aerobes capable of taking up acetate only during a short period $(<6 \mathrm{~h})$ under anaerobic conditions, as is well described for many PAOs and GAOs. They might also be involved in denitrification, as in the presence of $\mathrm{NO}_{3}^{-}$most bacteria in each group could take up labelled acetate after $6 \mathrm{~h}$ anaerobic incubation. Bac993-defined filaments did not take up organic substrates under any of the conditions tested.

Most bacterial cells hybridizing with Bet135 were able to store polyphosphates, as indicated by Neisser staining. All members of the other probe-defined groups were negative for Neisser staining. PHA (Nile blue staining) was present in most bacterial cells hybridizing with probes Bet135, Bet65 and Gam445 ( 50-90\%, naked eye estimation by counting 50 cells hybridizing with each probe). Filaments hybridizing with Bac993 were negative for Neisser and Nile blue staining.

\section{Distribution and abundance of the novel probe- defined microbial groups in different full-scale EBPR WWTPs}

The abundance of the new probe-defined microbial groups identified in this study was also investigated in 10 full-scale
EBPR WWTPs using quantitative FISH (Table 2). Some WWTPs (AAE, AAV, Egaa and Helsingborg) were sampled three times on different dates to get an impression of the temporal variation in individual WWTPs. The results showed that the six new probe-defined groups were present in all EBPR WWTPs investigated, but varied in abundance. The morphotypes of the probe-defined populations observed in all the WWTPs were identical to those in the Skagen WWTP.

Bacteroidetes consisting of the two newly identified groups were abundant (10-22\%) in all EBPR WWTPs examined. The Bac111-defined Bacteroidetes group of primarily epiphytic rods was the largest group in all sludge samples examined, in accordance with the clone library analysis and FISH analysis of the Skagen sludge. The group constituted 9-19\% of the total biovolume in the 10 WWTPs (Table 2). The Bac993-defined group was less abundant in all WWTPs, accounting for $1-6 \%$. The two probe-defined Bacteroidetes groups only showed small temporal variations in a specific WWTP, indicating that these Bacteroidetes were indeed important bacterial groups in full-scale EBPR WWTPs. Of the novel probe-defined groups in the Betaproteobacteria and the Gammaproteobacteria, only the Bet65-defined betaproteobacterial group was relatively abundant, making up 3-6\% in several EBPR WWTPs. All other novel probe-defined groups constituted less than $3 \%$ in all WWTPs investigated.

Table 2. Distribution and abundance of micro-organisms identified in this study in nutrient removal plants

\begin{tabular}{|c|c|c|c|c|c|}
\hline \multirow[t]{2}{*}{ Plant $^{*}$} & \multicolumn{5}{|c|}{ Biovolume (\%) of individual probe-defined groups $\dagger$} \\
\hline & Bac111 & Bac993 & Gam455 & Bet65 & Bet135 \\
\hline Skagen $(08-02-06)$ & $14-18$ & $1-2$ & $2-4$ & $2-4$ & $1-2$ \\
\hline AAE (15-02-05) & $10-12$ & $1-3$ & $1-3$ & $1-3$ & $1-2$ \\
\hline $\operatorname{AAE}(08-12-04)$ & $9-12$ & $4-6$ & $<1$ & $<1$ & $1-3$ \\
\hline AAE $(26-06-03)$ & $16-19$ & $2-3$ & $1-3$ & $1-3$ & $1-3$ \\
\hline AAV (06-02-06) & $13-15$ & $1-3$ & $<1$ & $<1$ & $1-3$ \\
\hline AAV (15-02-05) & $13-16$ & $2-3$ & $<1$ & $<1$ & $1-3$ \\
\hline AAVt (08-12-04) & $12-15$ & $1-3$ & $1-2$ & $<1$ & $1-3$ \\
\hline Egaa (10-01-06) & $13-14$ & $3-6$ & $1-3$ & $4-6$ & $<1$ \\
\hline Egaa (14-12-04) & $9-12$ & $1-3$ & $<1$ & $1-3$ & $<1$ \\
\hline Egaa $(26-06-03)$ & $10-12$ & $2-3$ & $1-3$ & $1-3$ & $<1$ \\
\hline Helsingborg (16-03-05) & $10-13$ & $1-3$ & $<1$ & $1-2$ & $1-2$ \\
\hline Helsingborg (12-10-04) & $11-14$ & $1-3$ & $<1$ & $1-3$ & $<1$ \\
\hline Helsingborg (01-07-04) & $13-15$ & $1-2$ & $<1$ & $1-3$ & $1-3$ \\
\hline Bjergmarken (01-05-06) & $12-15$ & $1-3$ & $<1$ & $<1$ & $<1$ \\
\hline Ejby Mølle (08-02-06) & $11-12$ & $1-2$ & $<1$ & $<1$ & $<1$ \\
\hline Odense Nordøst (07-02-06) & $12-15$ & $1-3$ & $<1$ & $<1$ & $1-3$ \\
\hline Varde $(05-02-06)$ & $17-19$ & $<1$ & $<1$ & $3-5$ & $<1$ \\
\hline Lynetten (04-02-06) & $10-13$ & $1-2$ & $<1$ & $<1$ & $<1$ \\
\hline Damhusåen (01-02-06) & $9-12$ & $1-3$ & $<1$ & $<1$ & $1-2$ \\
\hline
\end{tabular}

${ }^{\star}$ The dates (day-month-year) in parentheses are the dates the samples were taken.

$\dagger$ In all the WWTPs except the Skagen plant the Gam829-defined group constituted $<1 \%$ bacterial biovolume in each sample and is therefore not listed in the table. 


\section{DISCUSSION}

This paper presents the first detailed study, to our knowledge, of the structure and function of the microbial community in a full-scale EBPR WWTP, in contrast to many similar studies carried out on EBPR microbial communities enriched in laboratoary-scale reactors. The study showed that Bacteroidetes, mainly consisting of the Haliscomenobacter-related group defined by probe Bac111, were abundant in EBPR WWTPs; several novel abundant microbial groups belonging to the Betaproteobacteria and Gammaproteobacteria (putative PAOs and GAOs) were identified, and, for the first time, it was possible to detect most micro-organisms in a full-scale EBPR WWTP by using clone- or group-specific gene probes.

\section{Community structure in the Skagen WWTP as revealed by using the full-cycle RNA approach}

Clone library analysis and FISH generally agreed on the presence of many important microbial groups in the Skagen WWTP. These include betaproteobacterial RPAO and ammonia-oxidizing nitrosomonads, gammaproteobacterial GAOs (GB group), filamentous Chloroflexi and Nitrospira nitrite-oxidizing bacteria. As mentioned above, the important ecophysiological aspects of some of these bacteria are generally known. Several other probe-defined microbial groups belonging to the phyla Bacteroidetes, Proteobacteria and Chlorobi, and the Candidatus phylum TM7, were also present, but no or little ecophysiological data exist for these. There is a significant lack of consistency between the FISH and the clone library analyses on the presence of Gram-positive bacteria, especially Actinobacteria. FISH showed that Actinobacteria, mainly consisting of two probe-defined actinobacterial PAO groups, constituted $13 \%$ of the bacterial biovolume, while no actinobacterial clone was retrieved in the clone library analysis. This could be due to the difficulty of extracting DNA from Gram-positive bacteria (Beer et al., 2004), PCR bias and/or low cloning number (Head et al., 1998).

A high-resolution insight into the in situ composition of the microbial community in the Skagen WWTP was achieved. Quantitative FISH revealed that approximately $81 \%$ of all bacteria hybridizing with EUBmix could be hybridized with group- or clone-level probes (Fig. 3), indicating that most of the dominant micro-organisms had been identified. In agreement with other studies, Betaproteobacteria constituted a significant part (38\%), whereas Bacteroidetes, Gammaproteobacteria, Alphaproteobacteria and Actinobacteria were other important components. Assuming that all probe-defined groups, accounting for more than $1 \%$ of the total bacterial biovolume, consisted of closely related species or strains, it can be estimated that 15 probe-defined populations made up most of the important microbial groups. Although each probe-defined population may have a certain degree of microdiversity, this is an interesting result, showing that only relatively few species made up a significant part of the biovolume in the Skagen WWTP. It was noted that the sum of biovolumes measured with individual clone- or groupspecific probes was $103 \%$, slightly above $100 \%$ of the bacteria hybridizing with the EUBmix. This may have been caused by the presence of many Chloroflexi filaments (hybridizing with CFX1223 and GNSB-941) that were observed not to hybridize with the EUBmix probe, and by a certain cross-hybridization of some probes, e.g. Bet135 and RPAOmix. Furthermore, the use of different fluorescent labels for the FISH probes may have caused an overestimation of the various groups due to differences in the properties of the two labels applied (Bouvier \& del Giorgio, 2003).

By using FISH analyses, members of Bacteroidetes have only recently been reported to be present in a significant amount in activated-sludge WWTPs (Xia et al., 2007). In this study, both clone library analysis and quantitative FISH probing revealed that Bacteroidetes, mainly consisting of two probe-defined groups, constituted $10-22 \%$ of the total eubacterial biovolume in all 11 full-scale EBPR WWTPs investigated. They were also always present in the WWTPs sampled several times, showing that Bacteroidetes are one of the main components of the EBPR microbial communities and most probably have an important function. In agreement with this, we recently found that the epiflora hybridizing with probe Bac111 is involved in protein hydrolysis in activated sludge (Xia et al., 2007). Their detailed ecophysiology is presently being investigated.

The consistent presence and abundance of Bacteroidetes in EBPR WWTPs have been significantly underestimated in previous studies because the probes CF319a and CF319b, which are normally used to detect the Bacteroidetes (Cytophaga-Flavobacterium group), do not cover the members defined by probes Bac111 and Bac993, having at least one mismatch. Therefore, probes Bac111 and Bac993 should be used together with CF319a + b in future studies that employ FISH probing of Bacteroidetes in activated-sludge WWTPs.

\section{Biodiversity of the microbial community in the Skagen WWTP}

In total, 87 16S rRNA genes were retrieved from the Skagen WWTP and they only represent a small part of the total biodiversity. Using $97.0 \%$ as the threshold, the homogeneous coverage calculated was $19 \%$, indicating that only a small fraction of the biodiversity in the Skagen WWTP is represented by the $16 \mathrm{~S}$ rRNA gene sequences retrieved. The species richness calculated is 411 . It should, however, be regarded as a minimum richness value because, as analysed elsewhere (Juretschko et al., 2002), not all OTUs with more than $97.0 \%$ similarity (recently a more stringent standard of $99 \%$ similarity has been proposed; Stackebrandt \& Ebers, 2006) belong to one species and the primers used in PCR amplification of the $16 \mathrm{~S}$ rRNA gene did not cover all 
bacteria. To cover most of the biodiversity in the Skagen WWTP at least 400-500 clones would be required.

To our knowledge, no similar comprehensive study of EBPR WWTPs has been published. Therefore, it is not possible to make direct comparisons of the biodiversity found in this study with that of others. Only a single study on a full-scale industrial WWTP with nitrificationdenitrification has been conducted (Juretschko et al., 2002). The species richness is much larger for Skagen (411) than was estimated by Juretschko et al. (2002) for an industrial N-removal WWTP (89). The higher biodiversity is most probably due to the differences in process configuration and influent characteristics.

\section{Function of the dominant probe-defined microbial groups in the Skagen WWTP}

Many probe-defined groups present in the Skagen WWTP have been characterized physiologically. The ammoniaoxidizing bacteria and nitrite-oxidizing bacteria belonging to the genera Nitrosomonas and Nitrospira, respectively, are the important nitrifiers, whereas bacteria related to Aquaspirillum, Thauera sp., Rhodocyclus and Comamonadaceae sp. are likely to be involved in denitrification (Ginige et al., 2004; Juretschko et al., 2002; Kong et al., 2004; Thomsen et al., 2004, 2007). Bacteria known to take part directly in biological $\mathrm{P}$ removal (PAOs) are the RPAO and the actinobacterial PAOs, making up a total of $22 \%$, while the GAOs are the gammaproteobacterial GAOs of the GB group and those related to Defluviicoccus $(<1 \%)$, constituting at least $5 \%$ of the biomass in our study. This is in agreement with other full-scale screenings for PAOs and GAOs (Kong et al., 2004, 2005, 2006).

The ecophysiological investigations carried out in this study showed that the Bet135-, Bet65- and Gam445defined groups are potentially important microbial groups behaving as either PAOs or GAOs in full-scale EBPR WWTPs. The Bac993-defined group did not take up any of the organic substrates tested under any of the conditions examined, so their physiology is still unknown. The microbial groups defined by Bet135, Bet65 and Gam445 were consumers of short-chain fatty acids and a few other compounds under both anaerobic and aerobic conditions. Moreover, they could all store PHA. Of these, only Bet135defined coccobacilli were able to store polyphosphate. According to the EBPR biochemical models (Mino et al., 1998), such behaviour is typical for PAOs and GAOs in EBPR systems characterized by anaerobic/aerobic cycling. Such activities have also been demonstrated under in situ conditions for RPAO (Kong et al., 2004), gammaproteobacterial GAOs of the GB group (Kong et al., 2006) and Defluviicoccus-related GAOs (Burow et al., 2007).

The Bet135-defined group may be a group of putative PAOs behaving very similarly to RPAOs in terms of uptake of substrates, storage of PHA and polyphosphate (although an active $\mathrm{P}$ uptake/release ability has yet to be confirmed).
Phylogenetically, the Bet135-defined group is closely related to the genus Dechloromonas, which agrees with the observation that Betaproteobacteria other than RPAOs could also be PAOs (Beer et al., 2006). RPAOs defined by the PAOmix are not targeted (at least one mismatch) by Bet135, but the hybridization of some cells with both Bet135 and PAOmix shows that the specificity of these probes is still not completely clear, because none of these has been specified with proper references. Interestingly, the Bet135-defined group could most likely respire with $\mathrm{NO}_{3}^{-}$ and/or $\mathrm{NO}_{2}^{-}$(produced from reduction of $\mathrm{NO}_{3}^{-}$), suggesting that they may be involved in denitrification in full-scale EBPR WWTPs like some RPAO, and thus be involved in denitrification in addition to other abundant denitrifiers.

The Bet65- and Gam445-defined groups most probably functioned as GAOs because they, like the Competibacter and the Defluviicoccus-related GAOs (Burow et al., 2007), could take up acetate and pyruvate under anaerobic conditions and form PHA but not polyphosphate as a storage product. They were also potentially involved in the denitrification. This is the first time that Betaproteobacteria have been described to behave as GAOs (Seviour et al., 2003).

The results from this study confirm that linking the fullcycle rRNA approach for identification of key microorganisms with various in situ techniques for the study of their function is a powerful tool to reveal structure and function in EBPR WWTPs. Furthermore, the study has shown that although some micro-organisms involved in removal of $\mathrm{N}$ and $\mathrm{P}$ in full-scale EBPR WWTPs are still undescribed, most of the important species or groups have now been identified and important aspects of their physiology revealed. The need for future studies may therefore mainly be related to the understanding of key factors that regulate the community structure and how the systems can be managed for optimal performance.

\section{ACKNOWLEDGEMENTS}

This study was supported by the Danish Technical Research Council (grant no. 26-04-0115). We thank Jane Ildal for technical support.

\section{REFERENCES}

Adamczyk, J., Hesselsoe, M., Iversen, N., Horn, M., Lehner, A., Nielsen, P. H., Schloter, M., Roslev, P. \& Wagner, M. (2003). The isotope array, a new tool that employs substrate-mediated labeling of rRNA for determination of microbial community structure and function. Appl Environ Microbiol 69, 6875-6887.

Alm, E. W., Oerther, D. B., Larsen, N., Stahl, D. A. \& Raskin, L. (1996). The oligonucleotide probe database. Appl Environ Microbiol 62, 3557-3559.

Altschul, S. F., Gish, W., Miller, W., Myers, E. W. \& Lipman, D. J. (1990). Basic local alignment search tool. J Mol Biol 215, 403-410.

Amann, R. I. (1995). In situ identification of micro-organisms by whole cell hybridization with rRNA-targeted nucleic acid probes. In Molecular Microbial Ecology Manual, pp. MMEM-3.3.6/1-MMEM-3.3.6/15. 
Edited by A. D. L. Akkermans, J. van Elsas \& F. de Bruijn. London: Kluwer Academic Publications.

Amann, R. I., Binder, B. J., Olson, R. J., Chisholm, S. W., Devereux, R. \& Stahl, D. A. (1990). Combination of $16 \mathrm{~S}$ ribosomal-RNA-targeted oligonucleotide probes with flow-cytometry for analyzing mixed microbial populations. Appl Environ Microbiol 56, 1919-1925.

Beer, M., Kong, Y. H. \& Seviour, R. J. (2004). Are some putative glycogen accumulating organisms (GAO) in anaerobic:aerobic activated sludge systems members of the Alphaproteobacteria? Microbiology 150, 2267-2275.

Beer, M., Stratton, H. M., Griffiths, P. C. \& Seviour, R. J. (2006). Which are the polyphosphate accumulating organisms in full-scale activated sludge enhanced biological phosphate removal systems in Australia? J Appl Microbiol 100, 233-243.

Bjornsson, L., Hugenholtz, P., Tyson, G. W. \& Blackall, L. L. (2002). Filamentous Chloroflexi (green non-sulfur bacteria) are abundant in wastewater treatment processes with biological nutrient removal. Microbiology 148, 2309-2318.

Blackall, L. L., Stratton, H., Bradford, D., Dot, T. D., Sjorup, C., Seviour, E. M. \& Seviour, R. J. (1996). "Candidatus Microthrix parvicella", a filamentous bacterium from activated sludge sewage treatment plants. Int J Syst Bacteriol 46, 344-346.

Bouvier, T. \& del Giorgio, P. A. (2003). Factors influencing the detection of bacterial cells using fluorescence in situ hybridization (FISH): a quantitative review of published reports. FEMS Microbiol Ecol 44, 3-15.

Brosius, J., Dull, T. J., Sleeter, D. D. \& Noller, H. F. (1981). Gene organization and primary structure of a ribosomal-RNA operon from Escherichia coli. J Mol Biol 148, 107-127.

Burow, L. C., Kong, Y. H., Nielsen, J. L., Blackall, L. L. \& Nielsen, P. H. (2007). Abundance and ecophysiology of Defluviicoccus spp., glycogen-accumulating organisms in full-scale wastewater treatment processes. Microbiology 153, 178-185.

Cole, J. R., Chai, B., Farris, R. J., Wang, Q., Kulam, S. A., McGarrell, D. M., Garrity, G. M. \& Tiedje, J. M. (2005). The ribosomal database project (RDP-II): sequences and tools for high-throughput rRNA analysis. Nucleic Acids Res 33, D294-D296.

Crocetti, G. R., Hugenholtz, P., Bond, P. L., Schuler, A., Keller, J., Jenkins, D. \& Blackall, L. L. (2000). Identification of polyphosphateaccumulating organisms and design of $16 \mathrm{~S}$ rRNA-directed probes for their detection and quantitation. Appl Environ Microbiol 66, 1175-1182.

Crocetti, G. R., Banfield, J. F., Keller, J., Bond, P. L. \& Blackall, L. L. (2002). Glycogen-accumulating organisms in laboratory-scale and full-scale wastewater treatment processes. Microbiology 148, 3353-3364.

Daims, H., Bruhl, A., Amann, R., Schleifer, K. H. \& Wagner, M. (1999). The domain-specific probe EUB338 is insufficient for the detection of all Bacteria: development and evaluation of a more comprehensive probe set. Syst Appl Microbiol 22, 434-444.

Daims, H., Nielsen, J. L., Nielsen, P. H., Schleifer, K. H. \& Wagner, M. (2001). In situ characterization of Nitrospira-like nitrite oxidizing bacteria active in wastewater treatment plants. Appl Environ Microbiol 67, 5273-5284.

Ginige, M. P., Hugenholtz, P., Daims, H., Wagner, M., Keller, J. \& Blackall, L. L. (2004). Use of stable-isotope probing, full-cycle rRNA analysis, and fluorescence in situ hybridization-microautoradiography to study a methanol-fed denitrifying microbial community. Appl Environ Microbiol 70, 588-596.

Head, I. M., Saunders, J. R. \& Pickup, R. W. (1998). Microbial evolution, diversity, and ecology: a decade of ribosomal RNA analysis of uncultivated microorganisms. Microb Ecol 35, 1-21.
Hess, A., Zarda, B., Hahn, D., Haner, A., Stax, D., Hohener, P. \& Zeyer, J. (1997). In situ analysis of denitrifying toluene- and $m$ xylene-degrading bacteria in a diesel fuel-contaminated laboratory aquifer column. Appl Environ Microbiol 63, 2136-2141.

Hesselmann, R. P. X., Werlen, C., Hahn, D., van der Meer, J. R. \& Zehnder, A. J. B. (1999). Enrichment, phylogenetic analysis and detection of a bacterium that performs enhanced biological phosphate removal in activated sludge. Syst Appl Microbiol 22, 454-465.

Huber, T., Faulkner, G. \& Hugenholtz, P. (2004). Bellerophon: a program to detect chimeric sequences in multiple sequence alignments. Bioinformatics 20, 2317-2319.

Hugenholtz, P., Tyson, G. W., Webb, R. I., Wagner, A. M. \& Blackall, L. L. (2001). Investigation of candidate division TM7, a recently recognized major lineage of the domain bacteria with no known pureculture representatives. Appl Environ Microbiol 67, 411-419.

Juretschko, S., Loy, A., Lehner, A. \& Wagner, M. (2002). The microbial community composition of a nitrifying-denitrifying activated sludge from an industrial sewage treatment plant analyzed by the full-cycle rRNA approach. Syst Appl Microbiol 25, 84-99.

Kong, Y. H., Beer, M., Seviour, R. J., Lindrea, K. C. \& Rees, G. N. (2001). Structure and functional analysis of the microbial community in an aerobic: anaerobic sequencing batch reactor (SBR) with no phosphorus removal. Syst Appl Microbiol 24, 597-609.

Kong, Y., Ong, S. L., Ng, W. J. \& Liu, W.-T. (2002). Diversity and distribution of a deeply branched novel proteobacterial group found in anaerobic-aerobic activated sludge processes. Environ Microbiol 4, 753-757.

Kong, Y., Nielsen, J. L. \& Nielsen, P. H. (2004). Microautoradiographic study of Rhodocyclus-related polyphosphate accumulating bacteria in full-scale enhanced biological phosphorus removal plants. Appl Environ Microbiol 70, 5383-5390.

Kong, Y., Nielsen, J. L. \& Nielsen, P. H. (2005). Identity and ecophysiology of uncultured actinobacterial polyphosphate-accumulating organisms in full-scale enhanced biological phosphorus removal plants. Appl Environ Microbiol 71, 4076-4085.

Kong, Y., Xia, Y., Nielsen, J. L. \& Nielsen, P. H. (2006). Ecophysiology of a group of uncultured Gammaproteobacterial glycogen-accumulating organisms in full-scale enhanced biological phosphorus removal wastewater treatment plants. Environ Microbiol 8, 479-489.

Kragelund, C., Levantesi, C., Borger, A., Thelen, K., Eikelboom, D., Tandoi, V., Kong, Y. H., van der Waarde, J., Krooneman, J. \& other authors (2007). Identity, abundance and ecophysiology of filamentous Chloroflexi species present in activated sludge treatment plants. FEMS Microbiol Ecol 59, 671-682.

Kumar, S., Tamura, K. \& Nei, M. (2004). MEGA3: integrated software for Molecular Evolutionary Genetics Analysis and sequence alignment. Brief Bioinform 5, 150-163.

Lajoie, C. A., Layton, A. C., Gregory, I. R., Sayler, G. S., Taylor, D. E. \& Meyers, A. J. (2000). Zoogleal clusters and sludge dewatering potential in an industrial activated-sludge wastewater treatment plant. Water Environ Res 72, 56-64.

Lane, D. J. (1991). 16S/23S rRNA sequencing. In Nucleic Acid Techniques in Bacterial Systematics, pp. 115-176. Edited by E. Stackebrandt \& M. Goodfellow. London: Wiley.

Lee, N., Nielsen, P. H., Andreasen, K. H., Juretschko, S., Nielsen, J. L., Schleifer, K. H. \& Wagner, M. (1999). Combination of fluorescent in situ hybridization and microautoradiography - a new tool for structure-function analyses in microbial ecology. Appl Environ Microbiol 65, 1289-1297.

Loy, A., Horn, M. \& Wagner, M. (2003). probeBase: an online resource for rRNA-targeted oligonucleotide probes. Nucleic Acids Res 31, 514-516. 
Ludwig, W., Strunk, O., Westram, R., Richter, L., Meier, H., Yadhukumar, Buchner, A., Lai, T., Steppi, S. \& other authors (2004). ARB: a software environment for sequence data. Nucleic Acids Res 32, 1363-1371.

Maixner, F., Noguera, D. R., Anneser, B., Stoecker, K., Wegl, G., Wagner, M. \& Daims, H. (2006). Nitrite concentration influences the population structure of Nitrospira-like bacteria. Environ Microbiol 8, 1487-1495.

Manz, W., Amann, R., Ludwig, W., Vancanneyt, M. \& Schleifer, K. H. (1996). Application of a suite of $16 \mathrm{~S}$ rRNA-specific oligonucleotide probes designed to investigate bacteria of the phylum cytophagaflavobacter-bacteroides in the natural environment. Microbiology 142, 1097-1106.

Meier, H., Amann, R., Ludwig, W. \& Schleifer, K. H. (1999). Specific oligonucleotide probes for in situ detection of a major group of Gram-positive bacteria with low DNA G+C content. Syst Appl Microbiol 22, 186-196.

Mino, T., Van Loosdrecht, M. C. M. \& Heijnen, J. J. (1998). Microbiology and biochemistry of the enhanced biological phosphate removal process. Water Res 32, 3193-3207.

Mobarry, B. K., Wagner, M., Urbain, V., Rittmann, B. E. \& Stahl, D. A. (1996). Phylogenetic probes for analyzing abundance and spatial organization of nitrifying bacteria. Appl Environ Microbiol 62, $2156-2162$.

Neef, A. (1997). Anwendung der in situ Einzelzell-Identifizierung von Bakterien zur Populationsanalyse in komplexen mikrobiellen Biozönosen. Doctoral thesis, Technische Universität München.

Nielsen, A. T., Liu, W. T., Filipe, C., Grady, L., Molin, S. \& Stahl, D. A. (1999). Identification of a novel group of bacteria in sludge from a deteriorated biological phosphorus removal reactor. Appl Environ Microbiol 65, 1251-1258.

Roller, C., Wagner, M., Amann, R., Ludwig, W. \& Schleifer, K. H. (1994). In situ probing of Gram-positive bacteria with high DNA $\mathrm{G}+\mathrm{C}$ content using $23 \mathrm{~S}$ rRNA-targeted oligonucleotides. Microbiology 140, 2849-2858.

Rossello-Mora, R. A., Wagner, M., Amann, R. \& Schleifer, K. H. (1995). The abundance of Zoogloea ramigera in sewage treatment plants. Appl Environ Microbiol 61, 702-707.

Schauer, M. \& Hahn, M. W. (2005). Diversity and phylogenetic affiliations of morphologically conspicuous large filamentous bacteria occurring in the pelagic zones of a broad spectrum of freshwater habitats. Appl Environ Microbiol 71, 1931-1940.
Seviour, R. J., Lindrea, K. C., Griffiths, P. C. \& Blackall, L. L. (1999). The activated sludge process. In The Microbiology of Activated Sludge, pp. 44-74. Edited by R. J. Seviour \& L. L. Blackall. Dordrecht: Kluwer Academic Publishers.

Seviour, R. J., Mino, T. \& Onuki, M. (2003). The microbiology of biological phosphorus removal in activated sludge systems. FEMS Microbiol Rev 27, 99-127.

Singleton, D. R., Furlong, M. A., Rathbun, S. L. \& Whitman, W. B. (2001). Quantitative comparisons of 16S rRNA gene sequence libraries from environmental samples. Appl Environ Microbiol 67, 4374-4376.

Stackebrandt, E. \& Ebers, J. (2006). Taxonomic parameters revisited: tarnished gold standards. Microbiol Today 33, 152-155.

Thomsen, T. R., Nielsen, J. L., Ramsing, N. B. \& Nielsen, P. H. (2004). Micromanipulation and further identification of FISH-labelled microcolonies of a dominant denitrifying bacterium in activated sludge. Environ Microbiol 6, 470-479.

Thomsen, T. R., Kong, Y. \& Nielsen, P. H. (2007). Ecophysiology of abundant denitrifying bacteria in activated sludge. FEMS Microbiol Ecol 60, 370-382.

Tykesson, E., Blackall, L. L., Kong, Y., Nielsen, P. H. \& Jansen, J. L. (2006). Applicability of experience from laboratory reactors with biological phosphorus removal in full-scale plants. Water Sci Technol 54, 267-275.

Wagner, M. \& Loy, A. (2002). Bacterial community composition and function in sewage treatment systems. Curr Opin Biotechnol 13, 218-227.

Wallner, G., Amann, R. \& Beisker, W. (1993). Optimizing fluorescent in situ hybridization with ribosomal-RNA-targeted oligonucleotide probes for flow cytometric identification of microorganisms. Cytometry 14, 136-143.

Wong, M. T., Mino, T., Seviour, R. J., Onuki, M. \& Liu, W. T. (2005). In situ identification and characterization of the microbial community structure of full-scale enhanced biological phosphorous removal plants in Japan. Water Res 39, 2901-2914.

Xia, Y., Kong, Y. H. \& Nielsen, P. H. (2007). In situ detection of protein-hydrolyzing microorganisms in activated sludge. FEMS Microbiol Ecol 60, 156-165.

Edited by: H. Daims 